\title{
Comparing laparoscopic cholecystectomy in patients with chronic obstructive pulmonary disease under spinal anesthesia and general anesthesia
}

\author{
Mehmet Bayrak ${ }^{1,2^{*}}$ (D) and Yasemin Altıntas
}

\begin{abstract}
Background: Epidemiological data demonstrate that the worldwide prevalence of chronic obstructive pulmonary disease is increasing. These patients have an increased risk of mortality and morbidity and have constant limitations in airflow. Comparing laparoscopic cholecystectomy (LC) in patients with chronic obstructive pulmonary disease (COPD) under spinal anesthesia (SA) and general anesthesia (GA).

Methods: We prospectively evaluated COPD patients who underwent laparoscopic cholecystectomy under general anesthesia (Group 1, $n=30$ ) or spinal anesthesia (Group 2, $n=30$ ) in our clinic between January 2016 and January 2018. Patients with COPD were further divided into groups according to their preoperative stages (Stage 1-4). Intraoperative vital findings, postoperative pain, complications, and length of hospitalization were compared between the general (GA) and spinal anesthesia (SA) groups.

Results: The mean age of the patients in the GA group was $61.0 \pm 6.7$ years and was $61.0 \pm 7.7$ years in the SA group. In the GA and SA groups, the mean ASA score was $2.8 \pm 0.6$ and $2.9 \pm 0.6$, respectively, the mean operation duration was $31.7 \pm 5.1$ and $30.6 \pm 5.1 \mathrm{~min}$, respectively, and the length of hospitalization was $3.2 \pm 1.7$ and $1.5 \pm 0$. 5 days, respectively. The partial carbon dioxide rates $(\mathrm{PaCO} 2)$ at the postoperative 5 th and 20th minutes were lower in the SA group than in the GA group. Further, the requirement for postoperative analgesia was lower in the SA group, and the length of hospitalization was significantly shorter in the SA group. There was no significant difference between the two groups in terms of operation duration.

Conclusion: Laparoscopic cholecystectomy is a rather safe procedure for COPD patients under general and spinal anesthesia. However, spinal anesthesia is preferred over general anesthesia as it has better postoperative analgesia and causes no impairment of pulmonary functions.
\end{abstract}

Keywords: COPD, Cholecystectomy, Laparoscopic, Regional anesthesia, Spinal anesthesia

\section{Background}

Patients with chronic obstructive pulmonary disease (COPD) have an increased risk of mortality and morbidity and have continuous limitations in airflow. These limitations are diagnosed by taking the ratio of forced expiratory volume in $1 \mathrm{~s}$ (FEV1) to forced vital capacity (FVC). The severity of limitations in airflow is determined solely by a

\footnotetext{
* Correspondence: drmehmetbayrak@hotmail.com

'Ortadogu Hospital, 01360 Adana, Turkey

${ }^{2}$ Ortadogu Hospital, Ziyapasa mahallesi 67055 sokak no:1, Adana, Turkey
}

patient's FEV1, which has been shown to predict COPD patient mortality [1].

Several meta-analyses and systematic reviews have reported an increasing worldwide prevalence of COPD that can be attributed to smoking, increased life expectancy, and less active lifestyles. For adults older than 40 years, COPD's worldwide prevalence (as defined physiologically) is $\sim 9-10 \%[2,3]$. This high prevalence is putting a burden on both surgeons and anesthesiologists, who are both seeing an increase in the volume of high-risk respiratory patients. These high-risk patients

(c) The Author(s). 2018 Open Access This article is distributed under the terms of the Creative Commons Attribution 4.0 International License (http://creativecommons.org/licenses/by/4.0/), which permits unrestricted use, distribution, and reproduction in any medium, provided you give appropriate credit to the original author(s) and the source, provide a link to the Creative Commons license, and indicate if changes were made. The Creative Commons Public Domain Dedication waiver (http://creativecommons.org/publicdomain/zero/1.0/) applies to the data made available in this article, unless otherwise stated. 
who are undergoing endoscopic procedures, especially those with COPD, have unique issues that require careful consideration by anesthesiologists. Currently, general anesthesia (GA) is used for the majority of laparoscopic procedures. However, more recent studies have indicated that regional anesthesia (RA) may be a better choice for certain patients [4].

Laparoscopic cholecystectomy (LC) was approved for use in 1988, and since then, it has been used as the gold standard treatment method for symptomatic cholelithiasis [5]. Patients undergoing LC are typically given GA and are intubated endotracheally in order to prevent respiratory embarrassment and aspiration due to pneumoperitoneum. However, recent studies have revealed that RA may be more beneficial than GA in these patients [4, 6-8].

During LC, insufflation with carbon dioxide (CO2) can cause pneumoperitoneum, in which the venous pressure is lower than the intra-abdominal pressure (IAP), preventing the resorption of $\mathrm{CO} 2$ and causing hypercapnia. Respiratory effects of pneumoperitoneum can be reduced lung volume, increased peak airflow pressure, and reduced pulmonary compliance $[3,9]$.

COPD severity should be assessed with a preoperative exam, including a comprehensive medical history, spirometry, and measurement of arterial blood gas. It is well known that advanced COPD patients have adverse outcomes when given GA with tracheal intubation and intermittent positive pressure ventilation (IPPV). These patients may have an increased rate of pulmonary complications following surgery, and are more susceptible to hypoxemia, laryngospasm, barotrauma, bronchospasm, and cardiovascular instability. Therefore, many believe that RA is a better choice than GA for these patients. Additionally, it should be noted that spinal and epidural anesthesia (when given at the lumbar level) do not affect respiratory function $[7,10-12]$.

In our clinic, laparoscopic cholecystectomy (LC) is generally performed under GA. However, we recently performed LC under SA for patients who could not tolerate GA, including COPD patients undergoing upper abdominal surgery. Therefore, in the current study, we analyzed the outcomes of COPD patients who underwent LC with GA and SA.

\section{Methods}

Patients with COPD admitted for LC were given the choice of spinal anesthesia instead of general anesthesia. The choice of different anesthesia was part of our routine standard care. Spinal anesthesia is a commonly used method in both laparoscopic cholecystectomy and other upper abdominal operations in our clinic. All volunteers provided informed consent. Written approval was obtained from Cukurova University Faculty of Medicine Clinical Ethical Board. 30 COPD patients had LC under
GA (Group 1) and another 30 COPD patients had LC under SA (Group 2). The age, gender, ASA scores, preoperative spirometer findings (FEV1, FEV1/FVC), concomitant systemic diseases (hypertension, diabetes mellitus, coronary artery disease) were evaluated. Exclusion criterias for spinal anesthesia was upper abdominal surgery and body mass index (BMI) over 55 .

The spirometry test records from every patient were used to determine COPD staging [10] and ASA scores (American Society of Anesthesiology).

During surgery, every patient's vitals were monitored and recorded, including invasive systemic blood pressure, peripheral oxygen saturation $(\mathrm{SpO} 2)$ via pulse oximetry, and electrocardiography. Following Allen's test, $\mathrm{PaCO} 2$ was measured by right or left radial artery cannulation.

Group 1 (the GA group) received $0.6 \mathrm{mg} / \mathrm{kg}$ rocuronium bromide, $2 \mathrm{mg} / \mathrm{kg}$ propofol, and $2 \mu \mathrm{g} / \mathrm{kg}$ fentanyl. After $90-120$ s $100 \%$ oxygenation, these patients underwent orotracheal intubation. Maintenance of anesthesia was performed using $1-3 \%$ sevoflurane in $50 \%$ nitrous oxide $/ 50 \%$ oxygen.

Group 2 (the SA group) received their anesthesia while sitting. First, the patients were injected with $1 \%$ xylocaine, and then they underwent lumbar puncture with a 25 gauge needle in the L2-L3 intervertebral space. Then, they were given an intrathecal injection of $25 \mathrm{mg}$ fentanyl and $3 \mathrm{ml}$ hyperbaric bupivacaine (0.5\%), following which they were told to lay supine for 5 minutes. LC was performed when the patient achieved a sensory level of T4 dermatome.

Patients who did not immediately reach the T4 level were put in a Trendelenburg position, and they were monitored every 5 minutes until the T4 level was reached. The surgery commenced as soon as the patient reached the T4 dermatome level. Ephedrine $5 \mathrm{mcg}$ was given in incremental intermittent IV boluses in order to stop the mean arterial blood pressure (MAP) from dropping more than $20 \%$ under the pre-anesthetic level. A fentanyl bolus of $25 \mathrm{mcg}$ was repeated at 5 minute intervals for shoulder pain $(\max 50 \mathrm{mcg})$. We recorded all incidents of intraoperative nausea/vomiting, hypotension, and right shoulder pain.

Each patient was put in the supine, reverse Trendelenburg position with a right lateral tilt up with his/her arms fully abducted. Patients were tilted the smallest amount possible in order to facilitate exposure of their gallbladders (i.e., we minimally used the reverse Trendelenburg position and right shoulder elevation). A pressure of 10-12 mmHg was used for pneumoperitoneum, and a flow rate of $2 \mathrm{~L} / \mathrm{min}$ (gradually increased to $5 \mathrm{~L} /$ min) was used for the initial insufflation of $\mathrm{CO} 2$. LC was performed using a standard three-trocar technique with a zero-degree optical scope. Gallbladder dissection began 
Table 1 Distribution of demographic variables

\begin{tabular}{|c|c|c|c|c|c|c|c|}
\hline & \multicolumn{4}{|c|}{ Anesthesia method } & \multicolumn{3}{|c|}{ Total } \\
\hline & \multicolumn{2}{|c|}{ General } & \multicolumn{2}{|c|}{ Spinal } & \multirow[b]{2}{*}{$\mathrm{n}$} & \multirow[b]{2}{*}{$\%$} & \multirow[b]{2}{*}{$p$} \\
\hline & $\mathrm{n}$ & $\%$ & $n$ & $\%$ & & & \\
\hline \multicolumn{8}{|l|}{ Gender } \\
\hline M & 20 & 66.7 & 22 & 73.3 & 42 & 70.0 & \multirow[t]{2}{*}{0.779} \\
\hline $\mathrm{F}$ & 10 & 33.3 & 8 & 26.7 & 18 & 30.0 & \\
\hline BMI & 30 & $\begin{array}{l}34.80 \pm \\
5.41\end{array}$ & 30 & $\begin{array}{l}33.47 \\
\pm 5.99\end{array}$ & 60 & $\begin{array}{l}34.13 \pm \\
5.70\end{array}$ & 0.369 \\
\hline \multicolumn{8}{|l|}{ Asa Score } \\
\hline 2 & 9 & 30.0 & 7 & 23.3 & 16 & 26.7 & \multirow[t]{3}{*}{0.835} \\
\hline 3 & 17 & 56.7 & 19 & 63.3 & 36 & 60.0 & \\
\hline 4 & 4 & 13.3 & 4 & 13.3 & 8 & 13.3 & \\
\hline \multicolumn{8}{|c|}{ Non-COPD diseases } \\
\hline None & 5 & 16.7 & 7 & 23.3 & 12 & 20.0 & \multirow[t]{6}{*}{0.214} \\
\hline DM & 0 & 0.0 & 4 & 13.3 & 4 & 6.7 & \\
\hline $\mathrm{HT}$ & 19 & 63.3 & 15 & 50.0 & 34 & 56.7 & \\
\hline HT- DM & 5 & 16.7 & 2 & 6.7 & 7 & 11.7 & \\
\hline HT- DM CAD & 1 & 3.3 & 1 & 3.3 & 2 & 3.3 & \\
\hline CAD- HT & 0 & 0.0 & 1 & 3.3 & 1 & 1.7 & \\
\hline \multicolumn{8}{|l|}{ COPD stage } \\
\hline 1 & 12 & 40.0 & 13 & 43.3 & 25 & 41.7 & \multirow[t]{3}{*}{0.962} \\
\hline 2 & 14 & 46.7 & 13 & 43.3 & 27 & 45.0 & \\
\hline 3 & 4 & 13.3 & 4 & 13.3 & 8 & 13.3 & \\
\hline
\end{tabular}

at the triangle of Calot with the identification and clipping of both the artery and cystic duct, followed by mobilization from the liver bed. A subhepatic drain was inserted after the gallbladder was removed.

The preoperative values of $\mathrm{SpO} 2$, arterial oxygen saturation $(\mathrm{SaO} 2), \mathrm{PaCO} 2$, and arterial partial oxygen pressure $(\mathrm{PaO} 2)$ were recorded for each patient. $\mathrm{PaCO} 2$ was recorded $5 \mathrm{~min}$ following anesthesia induction and at 5 and $20 \mathrm{~min}$ of insufflation. $\mathrm{PaCO} 2$ was also measured

Five min following extubation and 20 min postoperatively. The duration of operation was recorded for each patient.

\section{Statistical method}

The SPSS 17.0 packet program was used to analyze the data. Categorical measurements were summarized as numbers and percentages, and continuous measurements were summarized as means and standard deviations (or as medians and minimums-maximums when applicable). Categorical variables were compared with the Chi square test or Fisher test. Distributions were controlled, and Student's $t$ test was used to compare continuous measurements between the groups. Repeated Measures Variance Analyses were used to determine changes in variables according to the groups over time. Values of $p<0.05$ were considered significant.

\section{Results}

Demographic characteristics of the patients are presented in Tables 1 and 2. Laparoscopic cholecystectomy was performed under spinal anesthesia (30 patients) or general anesthesia (30 patients). None of the patients in either group was transferred to open surgery.

All of the LC patients well-tolerated the spinal anesthesia, and only 10 (33.3\%) experienced postoperative shoulder pain. This pain was relieved by shoulder massage in 5 patients (16.7\%). The other 5 patients (16.7\%) required analgesia with $25-50 \mathrm{mcg}$ fentanyl. Preoperative hypotension occurred in 2 patients $(6.7 \%)$, and both returned to normal with ephedrine $5 \mathrm{mg}$. Bradycardia occurred in 1 patient (3.3\%), and normocardia was maintained with $0.25 \mathrm{mg}$ atropine. Urinary retention occurred in 2 patients $(6.7 \%)$ in the postoperative period, and therefore, urinary catheter was inserted. One patient experienced postoperative headache, and none of the patients needed endotracheal entubation.

Of the patients who underwent general anesthesia (GA), 1 experienced postoperative hypotension (3.3\%), which was recovered by $5 \mathrm{mg}$ ephedrine. Tachycardia occurred in 2 patients, which was recovered by increasing the respiration rate in the anesthesia device. Four patients (13.3\%) required postoperative mechanic ventilation due to hypercarbia and acidosis. Non-invasive continuous positive airway pressure (CPAP) was administered to 2 patients for 2 hours. Two patients with Stage 3 COPD required prolonged entubation; one of these patients was weaned after 8 hours, and the other after 12 hours.

$\mathrm{PaCO} 2$ values for both groups are shown in Fig. 1. No significant difference was determined in each group with regards to preoperative $\mathrm{PaCO} 2$ levels, or at the $5^{\text {th }}$ and $20^{\text {th }}$ minutes of insufflation. However, $\mathrm{PaCO} 2$ measurements

Table 2 Distribution of demographic variables

\begin{tabular}{|c|c|c|c|c|c|c|c|}
\hline & \multicolumn{4}{|c|}{ Anesthesia method } & \multirow{2}{*}{\multicolumn{2}{|c|}{ Total }} & \multirow[b]{3}{*}{$p$} \\
\hline & \multicolumn{2}{|l|}{ General } & \multicolumn{2}{|l|}{ Spinal } & & & \\
\hline & Mean \pm SD & $\begin{array}{l}\text { Median } \\
\text { (Min-Max) }\end{array}$ & Mean \pm SD & $\begin{array}{l}\text { Median } \\
\text { (Min-Max) }\end{array}$ & Mean \pm SD & $\begin{array}{l}\text { Median } \\
\text { (Min-Max) }\end{array}$ & \\
\hline Age & $61.0 \pm 6.7$ & $61(45-74)$ & $61.6 \pm 7.7$ & $62(44-78)$ & $61.3 \pm 7.1$ & $62(44-78)$ & 0.734 \\
\hline Pre-op Fev1 & $71.3 \pm 12.3$ & $73(45-85)$ & $71.1 \pm 13.5$ & $74(40-84)$ & $71.2 \pm 12.8$ & $73(40-85)$ & 0.952 \\
\hline
\end{tabular}




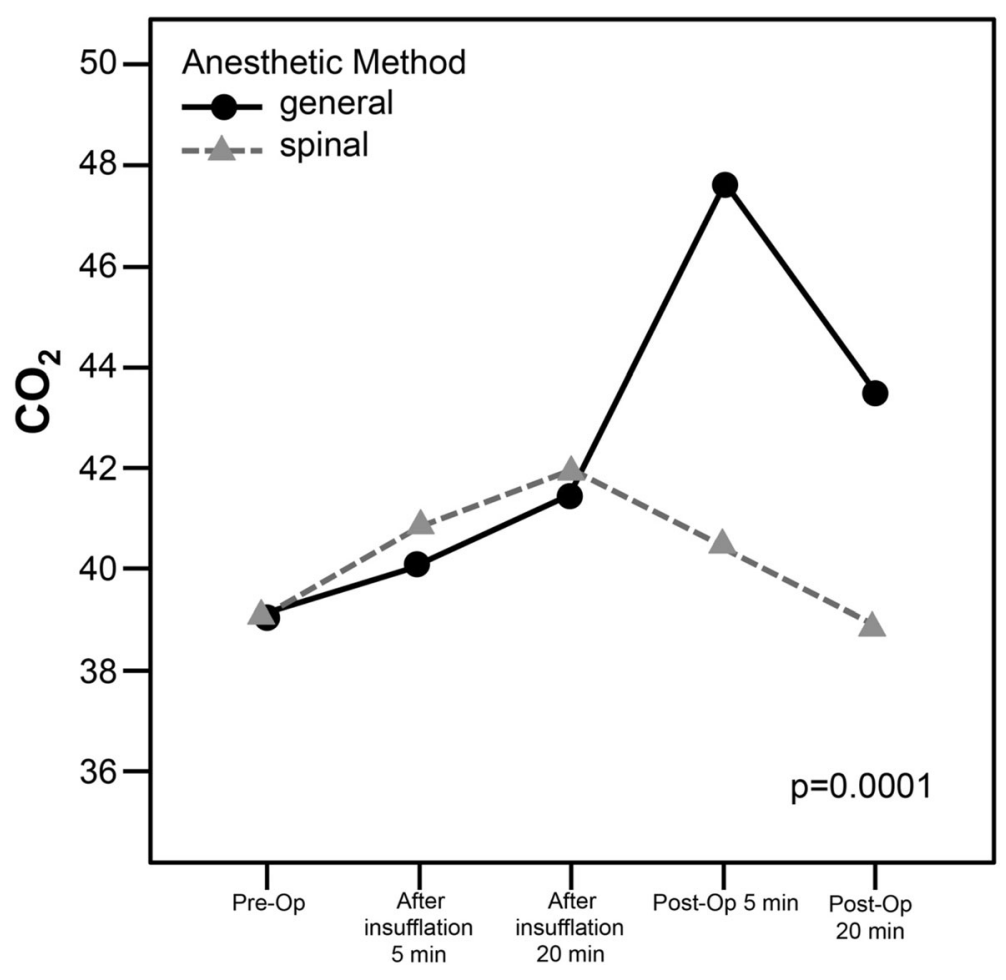

Fig. $1 \mathrm{PaCO} 2$ values for spinal and general anesthesia

were significantly higher in the general anesthesia group at the 5th and 20th postoperative minutes than in the SA group. In addition, the intergroup variation was significant with regards to the change in $\mathrm{PaCO} 2$ from the preoperative period to the 20th postoperative minutes $(p=0.0001)$.

The postoperative analgesia requirement is shown in Table 3. The postoperative analgesia requirement was significantly higher in the general anesthesia group.

Postoperative morbidity is shown in Table 4. Although there was no significant difference between the GA and SA groups, postoperative pulmonary functions were impaired more frequently in the GA group, and 4 GA patients required mechanical ventilation.

There was no significant difference in operation duration between the SA and GA groups. However, the

Table 3 Postoperative analgesia

\begin{tabular}{|c|c|c|c|c|c|c|c|}
\hline & \multicolumn{4}{|c|}{ Anesthesia method } & \multirow{2}{*}{\multicolumn{2}{|c|}{ Total }} & \multirow[b]{3}{*}{$p$} \\
\hline & \multicolumn{2}{|c|}{ General } & \multicolumn{2}{|c|}{ Spinal } & & & \\
\hline & $n$ & $\%$ & $\mathrm{n}$ & $\%$ & $\mathrm{n}$ & $\%$ & \\
\hline \multicolumn{8}{|c|}{ Post-Op Analgesia, first $2 \mathrm{~h}$} \\
\hline Yes & 30 & 100.0 & 0 & 0.0 & 30 & 50.0 & 0.0001 \\
\hline No & 0 & 0.0 & 30 & 100.0 & 30 & 50.0 & \\
\hline \multicolumn{8}{|c|}{ Post-Op Analgesia between 2 and $8 \mathrm{~h}$} \\
\hline Yes & 27 & 90.0 & 4 & 13.3 & 31 & 51.7 & 0.0001 \\
\hline No & 3 & 10.0 & 26 & 86.7 & 29 & 48.3 & \\
\hline
\end{tabular}

length of hospitalization was significantly lower in the SA group (Table 5).

\section{Discussion}

Earlier studies have reported that following abdominal surgery, COPD patients have a significant risk of pulmonary complications [13-15]. The respiratory system is known to be affected by opiates, general anesthetic agents, mechanical ventilation, and myo- relaxants [16]. Anesthetics are known to cause changes in mucociliary transport; however, it is also known that abdominal surgery (in particular, upper abdominal surgery) can have unwanted negative effects on the respiratory system, including closing volume, vital capacity (VC), functional residual capacity (FRC), and tidal volume (TV) $[17,18]$. Patients with COPD who are receiving anesthesia via inhalation or intravenously may have respiratory problems due to impaired mucociliary clearance. In addition, COPD patients may have respiratory problems due to $\mathrm{CO} 2$ pneumoperitoneum, which can cause diaphragm splinting systemic $\mathrm{CO} 2$ absorption. Therefore, the use of LC with newer anesthetic techniques (e.g., spinal, epidural blockage) may be a safer option for COPD patients [12]. Herein, we report the use general and spinal anesthesia for COPD patients undergoing laparoscopic cholecystectomy.

Several reports have shown that patients undergoing laparoscopy experience changes in their $\mathrm{CO} 2$ parameters. In a study including 30 patients who underwent LC 
Table 4 Postoperative morbidity

\begin{tabular}{|c|c|c|c|c|c|c|c|}
\hline & \multicolumn{4}{|c|}{ Anesthesia method } & \multirow{2}{*}{\multicolumn{2}{|c|}{ Total }} & \multirow[b]{3}{*}{$\mathrm{p}$} \\
\hline & \multicolumn{2}{|c|}{ General } & \multicolumn{2}{|c|}{ Spinal } & & & \\
\hline & $\mathrm{n}$ & $\%$ & $\mathrm{n}$ & $\%$ & $\mathrm{n}$ & $\%$ & \\
\hline \multicolumn{8}{|c|}{ Post-op Mechanical ventilation requirement } \\
\hline Yes & 4 & 13.3 & 0 & 0.0 & 4 & 6.7 & 0.122 \\
\hline No & 26 & 86.7 & 30 & 100.0 & 56 & 93.3 & \\
\hline \multicolumn{8}{|c|}{ Post-op Shoulder pain } \\
\hline Yes & 4 & 13.3 & 10 & 33.3 & 14 & 23.3 & 0.489 \\
\hline No & 26 & 86.7 & 20 & 67.7 & 46 & 76.7 & \\
\hline \multicolumn{8}{|c|}{ Post-Op Respiratory problem } \\
\hline Yes & 4 & 13.3 & 0 & 0.0 & 4 & 6.7 & 0.112 \\
\hline No & 26 & 86.7 & 30 & 100.0 & 56 & 93.3 & \\
\hline \multicolumn{8}{|c|}{ Post-op Urine retention } \\
\hline Yes & 0 & 0 & 2 & 6.7 & 2 & 3.3 & 0.472 \\
\hline No & 30 & 100.0 & 28 & 93.3 & 58 & 96.7 & \\
\hline \multicolumn{8}{|c|}{ Post-op Headache } \\
\hline Yes & 0 & 0 & 1 & 3.3 & 1 & 1.7 & 1.000 \\
\hline No & 30 & 100.00 & 29 & 96.7 & 59 & 98.3 & \\
\hline
\end{tabular}

under GA, Ozyuvacı E et al. found that these patients had a significantly higher postoperative $\mathrm{PaCO} 2$ when compared to preoperative levels [19]. Another study reported similar results [20]. Likewise, in our current study, the postoperative $\mathrm{PaCO} 2$ levels of the GA group were significantly higher than those in the SA group. In our current study, 4 patients in the GA group required mechanical ventilation due to postoperative hypercarbia and acidosis. On the other hand, patients in the SA group well-tolerated the procedure, and had no impairment in respiratory functions. The study by Gramatica et al. further supports the use of regional anesthesia (RA) for LC in advanced COPD cases, as they reported that all of the patients were stable throughout the surgery [11]. Likewise, in 1998, Pursnani et al reported that LC with RA could be safely used in severe COPD patients [12].

An important predictor of postoperative pulmonary function is effective analgesia. Since opioids can cause excessive sedation, spinal analgesia is a better choice, as it does not have this side effect and therefore lowers the risk of respiratory failure. Several studies have shown that RA can be useful for alleviating the postoperative pain of COPD patients [1, 11, 12, 19, 21, 22]. In our current study, results indicate that patients who underwent LC with SA had significantly less early analgesic requirement and postoperative pain compared to patients who underwent LC with GA; the SA patients had a reduction in pulmonary complications.

However, right shoulder pain is a complication of LC with SA. This pain is most likely due to the $\mathrm{CO} 2$ pneumoperitoneum irritating the diaphragm. Previous studies have shown that the incidence for intraoperative right shoulder pain (requiring iv fentanyl) was between 10 and $55.2 \%[7,8,11,23,24]$. In our current study, 10 (33.3\%) SA patients reported shoulder pain; 5 (16.7\%) of these required fentanyl, while $5(16.7 \%)$ were satisfied with shoulder massage.

Results of our current study revealed no significant difference in the average operation time between the GA and SA groups. This is most likely because we utilized an experienced surgical team who kept the operative times very short.

Other studies reported mean operation duration times as $47.4 \mathrm{~min}$ (Kalaivani V. et al.) and as $40 \mathrm{~min}$ (Pursnani et al.) [12, 25].

In our current study, 2 patients $(6.7 \%)$ in the SA group suffered from urinary retention; however, this complication did not increase their hospitalization times.

The mean length of the hospitalization was $1.5 \pm 0.5$ days in the SA group, which was significantly lower than that of the GA group ( $3.2 \pm 1.7$ days). It was determined that the SA patients had a faster recovery. A previous study by Mean Chi Hsun Hsieh et al. reported the mean length of the hospitalization to be $3.3 \pm 1.6$ dats in 20 patients with COPD who underwent LC with GA [21].

\section{Conclusion}

We conclude that laparoscopic cholecystectomy can be performed safely under GA and SA in patients with COPD. However, we recommend that SA should be used in COPD patients, as it reduces the risk of extubation, bronchoconstriction and respiratory depression, and decreases the requirement for postoperative mechanical ventilation, leading to a faster postoperative recovery. We believe that this study can be supported by larger randomized trials.

Table $\mathbf{5}$ Comparison of groups related to operation duration and length of hospitalization

\begin{tabular}{|c|c|c|c|c|c|c|c|}
\hline & \multicolumn{4}{|c|}{ Anesthesia method } & \multirow{2}{*}{\multicolumn{2}{|c|}{ Total }} & \multirow[b]{3}{*}{$p$} \\
\hline & \multicolumn{2}{|l|}{ General } & \multicolumn{2}{|l|}{ Spinal } & & & \\
\hline & Mean \pm SD & $\begin{array}{l}\text { Median } \\
\text { (Min-Max) }\end{array}$ & Mean \pm SD & $\begin{array}{l}\text { Median } \\
\text { (Min-Max) }\end{array}$ & Mean \pm SD & $\begin{array}{l}\text { Median } \\
\text { (Min-Max) }\end{array}$ & \\
\hline Operation duration (min) & $31.7 \pm 5.1$ & $33(23-45)$ & $30.6 \pm 5.1$ & $31(22-41)$ & $31.1 \pm 5.1$ & $32(22-45)$ & 0.318 \\
\hline Length of hospitalization (days) & $3.2 \pm 1.7$ & $3(2-10)$ & $1.5 \pm 0.5$ & $2(1-2)$ & $2.4 \pm 1.5$ & $2(1-10)$ & 0.0001 \\
\hline
\end{tabular}




\section{Additional file}

Additional file 1: Regional and general anesthesia COPD patients. (XLSX $14 \mathrm{~kb}$ )

\section{Abbreviations}

ASA: American society of anesthesiologists; ASA: American society of anesthesiologists; BMI: Body mass index; COPD: Chronic obstuctive pulmonary disease; FEV: Forced expitaroy volume; FVC: Forced vital capacity; GA: General anesthesia; IAP: Intra - abdominal pressure; IPPV: Intermittent positive pressure ventilation; L: Lumbar; L: Lumbar; LC: Laparoscopic cholecystectomy; MAP: Mean arterial blood pressure; NG: Nasogastric tube; Pa CO2: Partial carbon dioxide rates; RA: Regional anesthesia; SA: Spinal anesthesia; SaO2: Arterial oxygen saturation; SPO2: Blood oxygen saturation; T: Thoracal; T: Thoracic; VAS: Visual analogue scale; VC: Vital capacity

\section{Acknowledgements}

We acknowledge that English grammar editing and proof reading was done by "app.grammarly.com" web site.

\section{Funding}

This research received no specific grant from any funding agency in the public, commercial, or not-for-profit sectors.

\section{Availability of data and materials}

The datasets used and/or analysed during the current study are atteached as Additional file 1.

\section{Authors' contributions}

Both authors have made substantial contributions to the conception and design of the study, acquisition of data, or analysis and interpretation; drafting the article or revising it critically for important intellectual content and final approval of the version to be submitted. MB performed the operations and interpreted the patient's data regarding chronic obstructive pulmonary disease and YA analyzed and interpreted the patient data regarding chronic obstructive pulmonary disease and was a major contributer in writing the manuscript. Both authors read and approved the final manuscript.

\section{Ethics approval and consent to participate}

Written approval was obtained from Cukurova University Faculty of Medicine Clinical Ethical Board.

Written informed consent was obtained from all patients and parents.

\section{Consent for publication}

Not applicable.

\section{Competing interests}

The authors declare that they have no competing interests.

\section{Publisher's Note}

Springer Nature remains neutral with regard to jurisdictional claims in published maps and institutional affiliations.

Received: 18 May 2018 Accepted: 13 August 2018

Published online: 20 August 2018

\section{References}

1. Kim TH, Lee JS, Lee SW, Oh YM. Pulmonary complications after abdominal surgery in patients with mild-to-moderate chronic obstructive pulmonary disease. Int J Chron Obstruct Pulmon Dis. 2016;11:2785-96.

2. Halbert RJ, Natoli JL, Gano A, Badamgarav E, Buist AS, Mannino DM. Global burden of COPD: systematic review and meta-analysis. Eur Respir J. 2006; 28(3):523-32.

3. Khetarpal R, Bali K, Chatrath V, Bansal D. Anesthetic considerations in the patients of chronic obstructive pulmonary disease undergoing laparoscopic surgeries. Anesth Essays Res. 2016;10(1):7-12.

4. Vretzakis G, Bareka M, Aretha D, Karanikolas M. Regional anesthesia for laparoscopic surgery: a narrative review. J Anesth. 2014;28(3):429-46.
5. Gadacz TR, Talamini MA, Lillemoe KD, Yeo CJ. Laparoscopic cholecystectomy. Surg Clin North Am. 1990;70(6):1249-62.

6. Hausman MS Jr, Jewell ES, Engoren M. Regional versus general anesthesia in surgical patients with chronic obstructive pulmonary disease: does avoiding general anesthesia reduce the risk of postoperative complications? Anesth Analg. 2015;120(6):1405-12.

7. Sinha R, Gurwara AK, Gupta SC. Laparoscopic cholecystectomy under spinal anesthesia: a study of 3492 patients. J Laparoendosc Adv Surg Tech A. 2009; 19(3):323-7.

8. Tzovaras G, Fafoulakis F, Pratsas K, Georgopoulou S, Stamatiou G, Hatzitheofilou C. Spinal vs general anesthesia for laparoscopic cholecystectomy: interim analysis of a controlled randomized trial. Arch Surg. 2008;143(5):497-501.

9. Grabowski JE, Talamini MA. Physiological effects of pneumoperitoneum. J Gastrointest Surg. 2009;13(5):1009-16.

10. Celli BR, MacNee W, Force AET. Standards for the diagnosis and treatment of patients with COPD: a summary of the ATS/ERS position paper. Eur Respir J. 2004;23(6):932-46.

11. Gramatica L Jr, Brasesco OE, Mercado Luna A, Martinessi V, Panebianco G, Labaque F, et al. Laparoscopic cholecystectomy performed under regiona anesthesia in patients with chronic obstructive pulmonary disease. Surg Endosc. 2002:16(3):472-5

12. Pursnani KG, Bazza Y, Calleja M, Mughal MM. Laparoscopic cholecystectomy under epidural anesthesia in patients with chronic respiratory disease. Surg Endosc. 1998;12(8):1082-4.

13. Gupta H, Ramanan B, Gupta PK, Fang X, Polich A, Modrykamien A, et al. Impact of COPD on postoperative outcomes: results from a national database. Chest. 2013;143(6):1599-606.

14. Sakai RL, Abrao GM, Ayres JF, Vianna PT, Carvalho LR, Castiglia YM Prognostic factors for perioperative pulmonary events among patients undergoing upper abdominal surgery. Sao Paulo Med J. 2007;125(6):315-21.

15. Yang CK, Teng A, Lee DY, Rose K. Pulmonary complications after major abdominal surgery: National Surgical Quality Improvement Program analysis. J Surg Res. 2015;198(2):441-9.

16. Licker M, Schweizer A, Ellenberger C, Tschopp JM, Diaper J, Clergue F. Perioperative medical management of patients with COPD. Int J Chron Obstruct Pulmon Dis. 2007:2(4):493-515.

17. Hansen G, Drablos PA, Steinert R. Pulmonary complications, ventilation and blood gases after upper abdominal surgery. Acta Anaesthesiol Scand. 1977; 21(3):211-5

18. Meyers JR, Lembeck L, O'Kane H, Baue AE. Changes in functional residual capacity of the lung after operation. Arch Surg. 1975;110(5):576-83.

19. Ozyuvaci E, Demircioglu O, Toprak N, Topacoglu H, Sitilci T, Akyol O. Comparison of transcutaneous, arterial and end-tidal measurements of carbon dioxide during laparoscopic cholecystectomy in patients with chronic obstructive pulmonary disease. J Int Med Res. 2012:40(5):1982-7.

20. Iwasaka H, Miyakawa H, Yamamoto H, Kitano T, Taniguchi K, Honda N. Respiratory mechanics and arterial blood gases during and after laparoscopic cholecystectomy. Can J Anaesth. 1996;43(2):129-33.

21. Hsieh CH. Laparoscopic cholecystectomy for patients with chronic obstructive pulmonary disease. J Laparoendosc Adv Surg Tech A. 2003;13(1):5-9.

22. Imbelloni LE, Sant'anna R, Fornasari M, Fialho JC. Laparoscopic cholecystectomy under spinal anesthesia: comparative study between conventional- dose and low-dose hyperbaric bupivacaine. Local Reg Anesth. 2011:4:41-6.

23. Mehta PJ, Chavda HR, Wadhwana AP, Porecha MM. Comparative analysis of spinal versus general anesthesia for laparoscopic cholecystectomy: a controlled, prospective, randomized trial. Anesth Essays Res. 2010;4(2):91-5.

24. Yuksek YN, Akat AZ, Gozalan U, Daglar G, Pala Y, Canturk M, et al. Laparoscopic cholecystectomy under spinal anesthesia. Am J Surg. 2008; 195(4):533-6.

25. V S, Pujari VS, SM R, Hiremath BV, Bevinaguddaiah Y. Laparoscopic Cholecystectomy Under Spinal Anaesthesia vs. General Anaesthesia: a prospective randomised study. J Clin Diagn Res. 2014;8(8):NC01-4. 